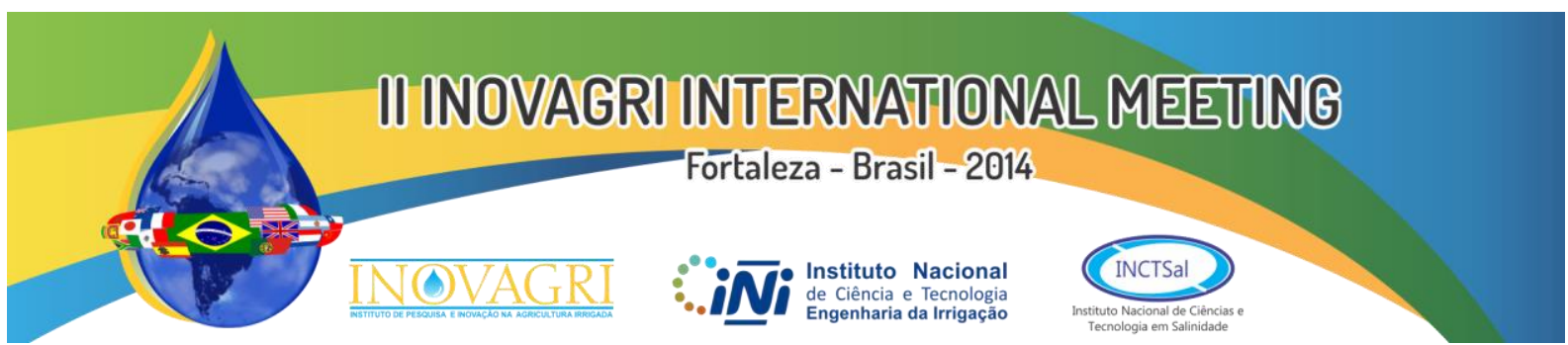

http://dx.doi.org/10.12702/ii.inovagri.2014-a172

\title{
NECESSIDADE DE SUPLEMENTAÇÃO HÍDRICA PARA O ARROZ DE TERRAS ALTAS EM QUATRO ESTADOS BRASILEIROS
}

\author{
A. B. Heinemann ${ }^{1}$, L. F. Stone ${ }^{2}$, S. C. da Silva ${ }^{3}$, A. da C. Moraes ${ }^{4}$
}

RESUMO: Nos estados de Goiás, Mato Grosso, Tocantins e Rondônia a cultura do arroz de terras altas apresenta alta variabilidade espacial e temporal na produtividade. Isso é condicionado pela ocorrência de estiagens de duas a três semanas, que são comuns nesses estados, e da baixa capacidade de armazenamento de água dos solos cultivados com arroz. Uma das alternativas para solucionar esse problema é a irrigação suplementar. Para a determinação da necessidade total de suplementação hídrica naqueles estados utilizou-se o modelo de simulação ORYZA2000 v.3 e dados climáticos de 32 anos. Consideraram-se oito datas de semeadura, de 01/11 a 10/01, e três solos com diferentes texturas, capacidades de água disponível e condutividade hidráulica. Simularam-se irrigações de $20 \mathrm{~mm}$ quando a água disponível no solo atingia 50\% da sua capacidade total. Foram gerados mapas das necessidades de suplementação hídrica para aqueles Estados, considerando-se a média dos 32 anos e as diferentes datas de semeadura e solos. Observou-se que a necessidade de suplementação hídrica aumenta à medida que a semeadura é realizada precoce ou tardiamente sendo mais influenciada pelos atributos físico-hídricos do solo. A suplementação hídrica tem mais efeito no aumento da produtividade do arroz para as regiões sudeste de Tocantins e nordeste de Goiás.

PALAVRAS-CHAVE: Oryza sativa, modelo de simulação, época de semeadura

\section{NEED FOR WATER SUPPLEMENTATION FOR UPLAND RICE IN FOUR BRAZILIAN STATES}

SUMMARY: In the states of Goiás, Mato Grosso, Rondônia, and Tocantins upland rice crop shows high spatial and temporal variability in productivity. It is conditioned by the occurrence of dry spells of two to three weeks, which are common in these states, and low water storage capacity of soils cropped with rice. An alternative to solving this problem is supplementary irrigation. The simulation model ORYZA2000 v.3 and climatic data of 32 years were used to determine the total need for water supplementation in those states. Eight sowing dates, from 01/11 to 01/10, and three soils with different textures, available water capacity, and hydraulic conductivity were considered. Irrigations of $20 \mathrm{~mm}$ were applied when the available soil water reached $50 \%$ of its total capacity. Maps of the need for water supplementation for those states, considering the 32-year average and the different sowing dates and soils, were generated. It was observed that the need for water supplementation increases as the sowing is performed early or later and it is more influenced by physical-hydric properties. The water supplementation has a greater effect on increasing the rice yield in southeast of Tocantins and northeast of Goiás.

KEYWORDS: Oryza sativa, simulation model, sowing time

${ }^{1}$ Doutor, Pesquisador, Embrapa Arroz e Feijão, Caixa Postal 179, CEP 75375-000, Santo Antônio de Goiás, GO. Fone (32) 35332153. e-mail: alexandre.heinemann@embrapa.br.

${ }^{2}$ Doutor, Pesquisador, Embrapa Arroz e Feijão, Santo Antônio de Goiás, GO.

${ }^{3}$ Mestre, Pesquisador, Embrapa Arroz e Feijão, Santo Antônio de Goiás, GO.

${ }^{4}$ Analista, Embrapa Arroz e Feijão, Santo Antônio de Goiás, GO.

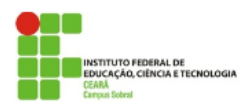




\section{INTRODUÇÃO}

Historicamente o cultivo do arroz (Oryza sativa L.) de terras altas assumiu papel importante como cultura pioneira no processo de ocupação agrícola do Cerrado, iniciado na década de 1960. Com a progressiva redução das áreas de abertura, em meados da década de 1980, a área cultivada com arroz sob o sistema de sequeiro foi sendo gradativamente reduzida. Ao longo dos anos a área semeada com arroz de terras altas decresceu em 68\%, passando de 3,1 milhões para 1,0 milhão de hectares de 1990 a 2012 (EMBRAPA, 2014). O aumento verificado na produtividade, que passou de 949 para $1630 \mathrm{~kg} \mathrm{ha}$ ', não foi suficiente para compensar a perda na produção em razão da diminuição da área cultivada. Apesar disso, o Brasil é um dos poucos países do mundo onde o arroz de terras altas desempenha papel de fundamental importância no abastecimento interno desse grão para a população, atuando como regulador de preços.

Uma das razões para o decréscimo da área cultivada com arroz de terras altas é o risco climático. Grande parte das lavouras está localizada na região do Cerrado, onde predominam latossolos com baixa capacidade de armazenamento de água (CAD). Durante a estação chuvosa (outubro-abril), quando é feito o cultivo do arroz, a distribuição das chuvas é irregular, sendo comum a ocorrência de estiagens de duas a três semanas. A alta demanda evapotranspirativa, aliada à característica dos solos, faz com que essas estiagens causem consideráveis decréscimos na produtividade do arroz (Stone \& Silveira, 2004).

A irrigação suplementar por aspersão pode minimizar os riscos de deficiência hídrica, contribuindo para a estabilidade da produção. Adicionalmente, pela redução do risco se poderá empregar mais tecnologia, o que propiciará maiores produtividades e melhor qualidade do produto. Rodrigues \& Arf (2002), em Selvíria, MS, no ano agrícola de 1999/00, verificaram incremento de 30\% na produtividade do arroz pelo uso da irrigação suplementar por aspersão. Para o mesmo local, o incremento alcançou 91\%, em 2000/01 (Soratto et al., 2002). Arf et al. (2001) verificaram, em ano com ocorrência de estiagens, que a irrigação suplementar promoveu incrementos na produtividade que variaram de 113 a $177 \%$.

Com a utilização da irrigação por aspersão questiona-se se o período de semeadura do arroz de terras altas que, dependendo da região vai de outubro a dezembro, não poderia ser modificado. Entretanto, além da precipitação pluvial, que pode ser suplementada ou substituída pela irrigação por aspersão, outros elementos climáticos, como temperatura e fotoperíodo, limitam o sucesso do cultivo do arroz em determinadas épocas do ano. Assim, vários autores (Sant'Ana, 1989; Arf et al., 2000) concluíram que a melhor época de semeadura do arroz irrigado por aspersão é a usual, podendo ser estendida, no Centro-Oeste, até a primeira quinzena de janeiro (Lobato \& Silva, 1995). Nesse período, o risco de perda da lavoura por problemas climáticos é reduzido e os custos de irrigação são menores.

Modelos de simulação do desenvolvimento, crescimento e produtividade de culturas são considerados excelente ferramenta para explorar opções de manejo. Referidos modelos sintetizam os processos ecofisiológicos do crescimento e desenvolvimento de culturas e permitem a extrapolação de resultados experimentais para diferentes práticas de manejo e condições climáticas (Bouman \& Laar, 2006). Dentre os modelos de crescimento se destaca o ORYZA2000, que simula as dinâmicas do crescimento, desenvolvimento e produtividade do arroz em condições potenciais (Kropff et al., 1994) e limitantes de água (Wopereis et al., 1996). Objetivou-se com este trabalho simular, com o modelo ORYZA2000, a necessidade de suplementação hídrica para o arroz de terras altas nos estados de Goiás, Mato Grosso, Tocantins e Rondônia, considerando oito datas de semeadura e três solos com diferentes atributos físico-hídricos.

\section{MATERIAL E MÉTODOS}

O modelo de simulação do desenvolvimento, crescimento e produtividade do arroz ORYZA2000 v.3 foi calibrado e validado para a cultivar de arroz de terras altas BRS Primavera. Para a calibração fenológica da iniciação da panícula, florescimento e maturação fisiológica foram utilizados quatro experimentos realizados em Santo Antônio de Goiás, GO (Figura 1a, b, c). Para a validação do 
florescimento, maturação fisiológica e da produtividade utilizaram-se dados de experimentos proveniente do programa de melhoramento de arroz de terras altas da Embrapa Arroz e Feijão realizados em Santo Antônio de Goiás, GO, em vários anos (Figura 1c, d, e). A calibração e validação do modelo para o acúmulo de matéria seca de folhas, caule, panícula e total foi realizada utilizando-se três experimentos realizados em Santo Antônio de Goiás, GO, nas safras de 2010/2011 (irrigada), 2009/2010 (não irrigada) e 2012/2013 (irrigada) (Figura 2).

Com o modelo calibrado, simularam-se a necessidade de suplementação hídrica para o arroz de terras altas nos estados de Goiás, Mato Grosso, Tocantins e Rondônia e o ganho em produtividade com o seu uso. Para tal, utilizaram-se 51 estações climáticas com dados diários de precipitação, temperatura máxima, mínima e radiação solar global no período de 1980 a 2012, provenientes da base de dados do Instituto Nacional de Meteorologia (INMET). Para determinar a área de atuação das estações meteorológicas utilizou-se o método de "Thissen", que considera a distância geográfica entre as estações climáticas. A distribuição geográfica das estações e suas respectivas áreas de atuação estão representadas na Figura 3. Três solos representativos da região de estudo foram considerados; argiloso (A), franco argiloso (FA) e franco argilo arenoso (FAA), baseado na textura e localização geográfica dos perfis provenientes do projeto RADAM, descritos em Benedetti et al. (2008). Os solos diferem na capacidade de água disponível $(40,25$ e $25 \mathrm{~mm}$ na camada de $0,50 \mathrm{~m}$ de profundidade para A, FA e FAA, respectivamente) e na condutividade hidráulica saturada $\left(107,77\right.$ e $52 \mathrm{~cm} \mathrm{dia}^{-1}$ para $\mathrm{A}, \mathrm{FA}$ e FAA, respectivamente).

Dois cenários foram simulados, não irrigado e irrigado. No cenário irrigado, simulou-se a aplicação de uma lâmina de $20 \mathrm{~mm}$ quando a água disponível no solo atingia $50 \%$ da sua capacidade total. O modelo ORYZA2000 foi executado para as combinações de clima, solo, cenários e oito datas de semeaduras $(01 / 11 ; 10 / 11 ; 20 / 11 ; 01 / 12 ; 10 / 12 ; 20 / 12 ; 30 / 12$ e $10 / 01)$ que englobam o período de semeadura do arroz de terras altas na região de estudo. O ganho em produtividade do arroz de terras altas em razão da irrigação suplementar, expresso em \%, foi calculado pela diferença entre a produtividade irrigada e não irrigada dividida pela produtividade irrigada multiplicada por 100, para as diferentes combinações. Os resultados obtidos com o modelo foram espacializados utilizando o método de interpolação pelo inverso da distância.

\section{RESULTADOS E DISCUSSÃO}

O modelo ORYZA2000 foi eficaz na determinação das variáveis fenológicas e do rendimento de grãos (Figuras 1d, e, f). Para o rendimento de grãos, o modelo apresentou maior variabilidade entre os dados observados e simulados (Figura 1f). Isso se deve ao fato de que, em alguns anos, no programa de melhoramento de arroz terras altas é aplicada irrigação suplementar com a finalidade de não deixar as plantas morrerem, a qual não é documentada. Esse modelo também foi eficaz em simular o acumulo de matéria seca de folhas, colmos e panículas (Figura 2a, b, c) e a tendência do índice de área foliar (Figura 2d, e, f), em função do ciclo da cultura, para ambientes irrigados e não irrigados.

A variação espacial da necessidade de suplementação hídrica para a cultura do arroz de terras altas nos estados de Goiás, Mato Grosso, Tocantins e Rondônia, considerando as oito datas de semeadura e os três solos, é apresentada nas Figuras 4 a 6 . A lâmina de irrigação suplementar requerida variou de 0 a $265 \mathrm{~mm}$, embora na maioria dos casos tenha ficado abaixo de $225 \mathrm{~mm}$. Stone \& Silveira (2004) relataram valores inferiores a $200 \mathrm{~mm}$ por ciclo para a região Centro-Oeste. As menores lâminas foram verificadas para Rondônia e Mato Grosso, devido às características do regime pluvial desses Estados, que sofre influência de sistemas que atuam na Amazônia como, por exemplo, CCMs (complexo convectivo de mesoescala) tropicais (Reboita et al., 2010). Já as regiões sudeste de Tocantins e nordeste de Goiás apresentaram a maior demanda por suplementação hídrica.

Comparando-se as Figuras 4, 5 e 6 observa-se o efeito dos diferentes solos na lâmina requerida. Em solo franco argiloso (Figura 5), ela variou de 0 a $265 \mathrm{~mm}$, enquanto em solo franco argilo arenoso (Figura 6) variou de 0 a $100 \mathrm{~mm}$. Os diferentes atributos físico-hídricos dos solos implicam em variação no aproveitamento da precipitação pluvial, refletindo em diferentes necessidades de suplementação hídrica. 
As datas iniciais e finais do período de semeadura apresentaram as maiores demandas por suplementação hídrica (Figura 4 a 6). Em estudo sobre simulação do manejo da adubação nitrogenada na cultura do arroz de terras altas, Stone \& Heinemann (2012) observaram, para GO, maior probabilidade de se obter altas produtividades com semeadura em datas mais precoces, a partir de primeiro de novembro. De fato, Silva \& Assad (2001) constataram que, para os estados de GO, MT, MS, MG, TO e BA, o risco de ocorrência de deficiência hídrica no estádio de enchimento dos grãos do arroz de terras altas se acentua quanto mais tarde for a semeadura, a partir de outubro, independente do solo e do ciclo da cultura. Heinemann et al. (2008) também verificaram que a cultura do arroz de terras altas, quando semeada em datas precoces (início de novembro), tem maior probabilidade de não sofrer deficiência hídrica severa.

Considerando um solo franco argilo arenoso e a data de semeadura que requer menor suplementação hídrica (20/11), observa-se que o incremento em produtividade com o uso da irrigação suplementar praticamente situou-se entre 5 e 30\%, tendo os estados de Rondônia e Mato Grosso apresentado as menores respostas (Figura 7). Para a data de 10/01, o incremento em produtividade para algumas regiões de Goiás e Tocantins chegou a 50\%. Para um solo franco argiloso, o incremento em produtividade atingiu $65 \%$, para as regiões sudeste de Tocantins e nordeste de Goiás.

\section{CONCLUSÕES}

A necessidade de suplementação hídrica é maior para semeaduras precoces ou realizadas tardiamente e é mais influenciada pelos atributos físico-hídricos dos solos.

A suplementação hídrica tem mais efeito no aumento da produtividade do arroz para as regiões sudeste de Tocantins e nordeste de Goiás.

\section{REFERÊNCIAS BIBLIOGRÁFICAS}

ARF, O.; RODRIGUES, R.A.F.; SÁ, M.E. de; CRUSCIOL, C.A.C. Influência da época de semeadura no comportamento de cultivares de arroz irrigado por aspersão em Selvíria, MS. Pesquisa Agropecuária Brasileira, v.35, n.10, p.1967-1976, 2000. http://dx.doi.org/10.1590/S0100$\underline{204 X 2000001000007}$

ARF, O.; RODRIGUES, R.A.F.; SÁ, M.E. de; CRUSCIOL, C.A.C. Resposta de cultivares de arroz de sequeiro ao preparo do solo e à irrigação por aspersão. Pesquisa Agropecuária Brasileira, v.36, n.6, p.871-879, 2001. http://dx.doi.org/10.1590/S0100-204X2001000600004

BENEDETTI, M.M.; SPAROVEK, G.; COOPER, M.; CURI, N; CARVALHO FILHO, A. de. Representatividade e potencial de utilização de um banco de dados de solos do Brasil. Revista Brasileira de Ciência do Solo, v.32, n.6, p.2591-2560, 2008. http://dx.doi.org/10.1590/S0100$\underline{06832008000600036}$

BOUMAN, B.A.M.; LAAR, H.H. van. Description and evaluation of rice growth model ORYZA2000 under nitrogen-limited conditions. Agricultural Systems, v.87, n.3, p.249-273, 2006. http://dx.doi.org/10.1016/j.agsy.2004.09.011

EMBRAPA. Socioeconomia. Disponível em: http://www.cnpaf.embrapa.br/socioeconomia/index.htm. Acesso em 10 jan. 2014.

HEINEMANN, A. B.; DINGKUHN, M.; LUQUET, D.; COMBRES, J. C.; CHAPMAN, S. Characterization of drought stress environments for upland rice and maize in central Brazil. Euphytica, v.162, n.3, p.395-410, 2008. http://dx.doi.org/10.1007/s10681-007-9579-z

KROPFF, M.J.; LAAR, H.H. van; MATHEWS, R.B. (ed.). ORYZA1, an ecophysiological model for irrigated lowland rice production. In: SARP Research Prooceedings. Wageningen: IRRI/AB-DLO, 1994. 110p.

LOBATO, E.J.V.; SILVA, S.C. da. Parâmetros meteorológicos, fenologia e produtividade do arroz de sequeiro sob condições de cerrado. Goiânia: Embrapa-CNPAF, 1995. 11p. (Comunicado Técnico, 30). 
REBOITA, M. S.; GAN, M. A., ROCHA, R. P. da; AMBRIZZI, T. Regimes de precipitação na América do Sul: uma revisão bibliográfica. Revista Brasileira de Meteorologia, v.25, n.2, p.185204, 2010. http://dx.doi.org/10.1590/S0102-77862010000200004

RODRIGUES, R.A.F.; ARF, O. Manejo de água em cultivares de arroz de terras altas. In: CONGRESSO DA CADEIA PRODUTIVA DE ARROZ, 1., REUNIÃO NACIONAL DE PESQUISA DE ARROZ, 7., 2002, Florianópolis, SC. Anais... Santo Antônio de Goiás: Embrapa Arroz e Feijão, 2002. p.365-368. (Documentos, 134).

SANT'ANA, E. P. Cultivo do arroz irrigado por aspersão. Informe Agropecuário, Belo Horizonte, v.14, n.161, p.71-75, 1989.

SILVA, S. C DA; ASSAD, E. D. Zoneamento de riscos climáticos para o arroz de sequeiro nos estados de Goiás, Mato Grosso, Mato Grosso do Sul, Minas Gerais, Tocantins e Bahia. Revista Brasileira de Agrometeorologia, v.9, n.3, p.536-543, 2001.

SORATTO, R.P.; RODRIGUES, R.A.F.; ARF, O. Manejo de água em cultivares de arroz irrigados por aspersão no sistema de plantio direto. In: CONGRESSO DA CADEIA PRODUTIVA DE ARROZ, 1., REUNIÃO NACIONAL DE PESQUISA DE ARROZ, 7., 2002, Florianópolis, SC. Anais... Santo Antônio de Goiás: Embrapa Arroz e Feijão, 2002. p.369-372. (Documentos, 134).

STONE, L.F.; HEINEMANN, A.B. Simulação do manejo do nitrogênio em arroz de terras altas com o modelo ORYZA/APSIM 2000. Revista Brasileira de Engenharia Agrícola e Ambiental, Campina Grande, v.16, n.6, p.611-617, 2012.

STONE, L.F.; SILVEIRA, P.M. da. Arroz irrigado por aspersão. Informe Agropecuário, Belo Horizonte, v.25, n.222, p.70-76, 2004.

WOPEREIS, M.C.S.; BOUMAN, B.A.M.; TUONG, T.P.; TEN BERGE, H.F.M.; KROPFF, M.J. ORYZA W: Rice growth model for irrigated and rainfed environments. In: SARP Research Proceedings. Wageningen: IRRI/AB-DLO, 1996. 159p.
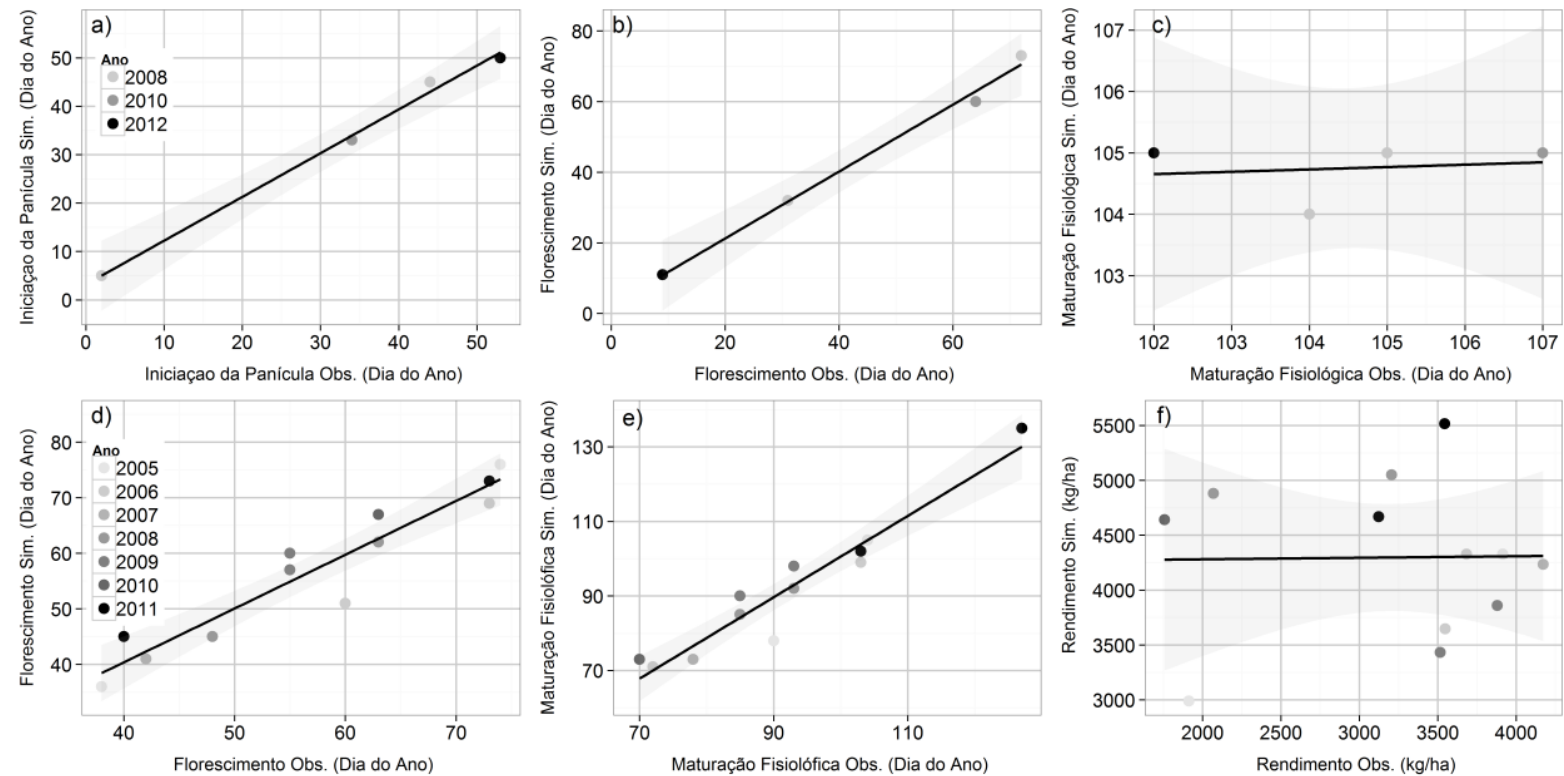

Figura 1. Regressão linear entre dados observados e simulados para os diversos experimentos (representados pelos anos) utilizados na calibração da fenologia para: a) iniciação da panícula; b) florescimento e c) maturação fisiológica e na validação para: d) florescimento; e) maturação fisiológica e e) rendimento, para a cultivar BRS Primavera. A faixa cinza representa o intervalo de confiança a 5\%. 

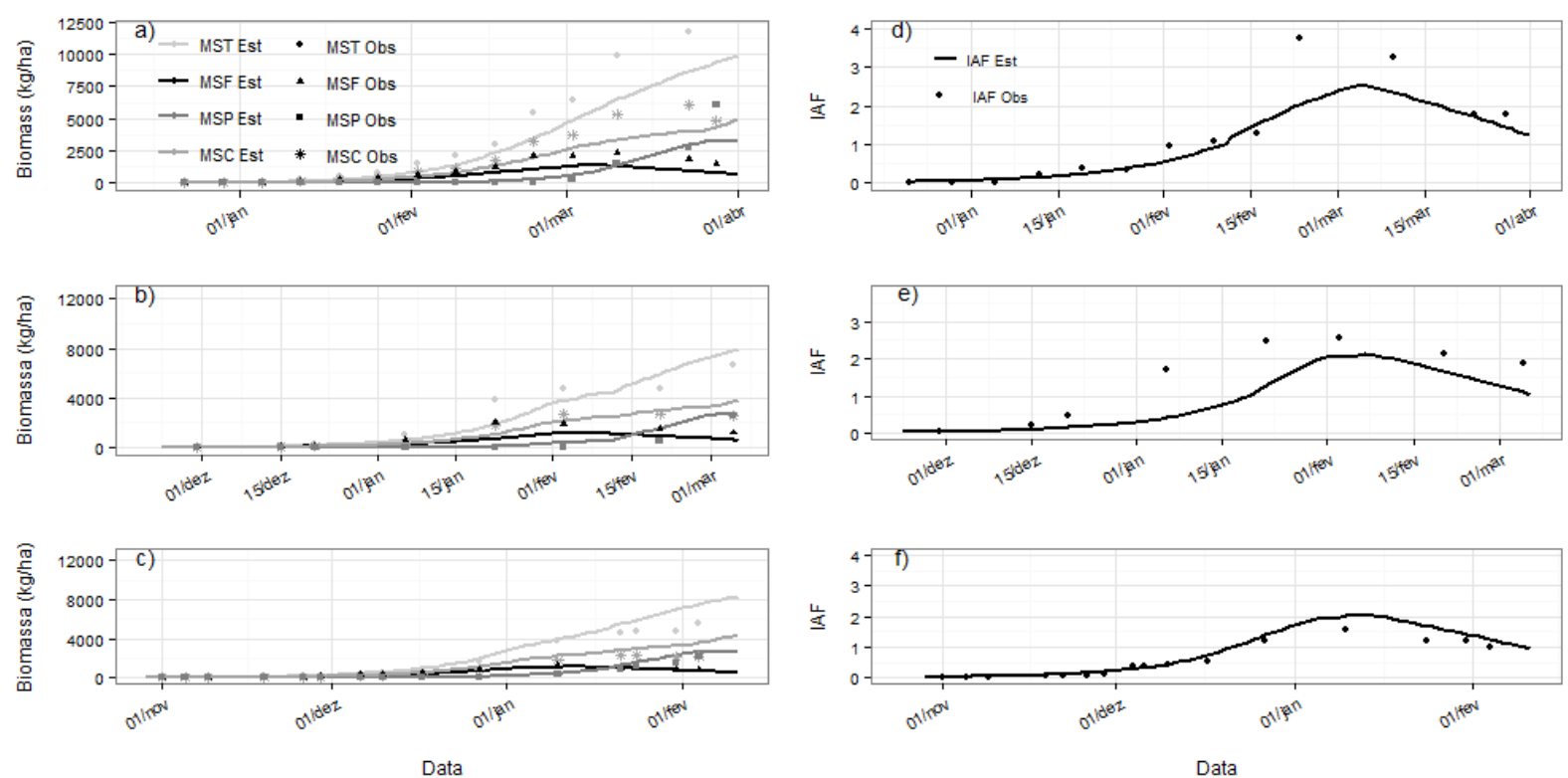

Figura 2. Desempenho do modelo ORYZA2000 para simular o desenvolvimento da matéria seca total (MST), de folhas (MSF), do colmo (MSC), panículas (MSP) e índice de área foliar (IAF) para: a) e d) safra irrigada 2010/2011; b) e e) não irrigada 2009/2010 e c) e f) irrigada 2012/2013. O ponto representa os dados observados e a linha contínua os dados simulados.

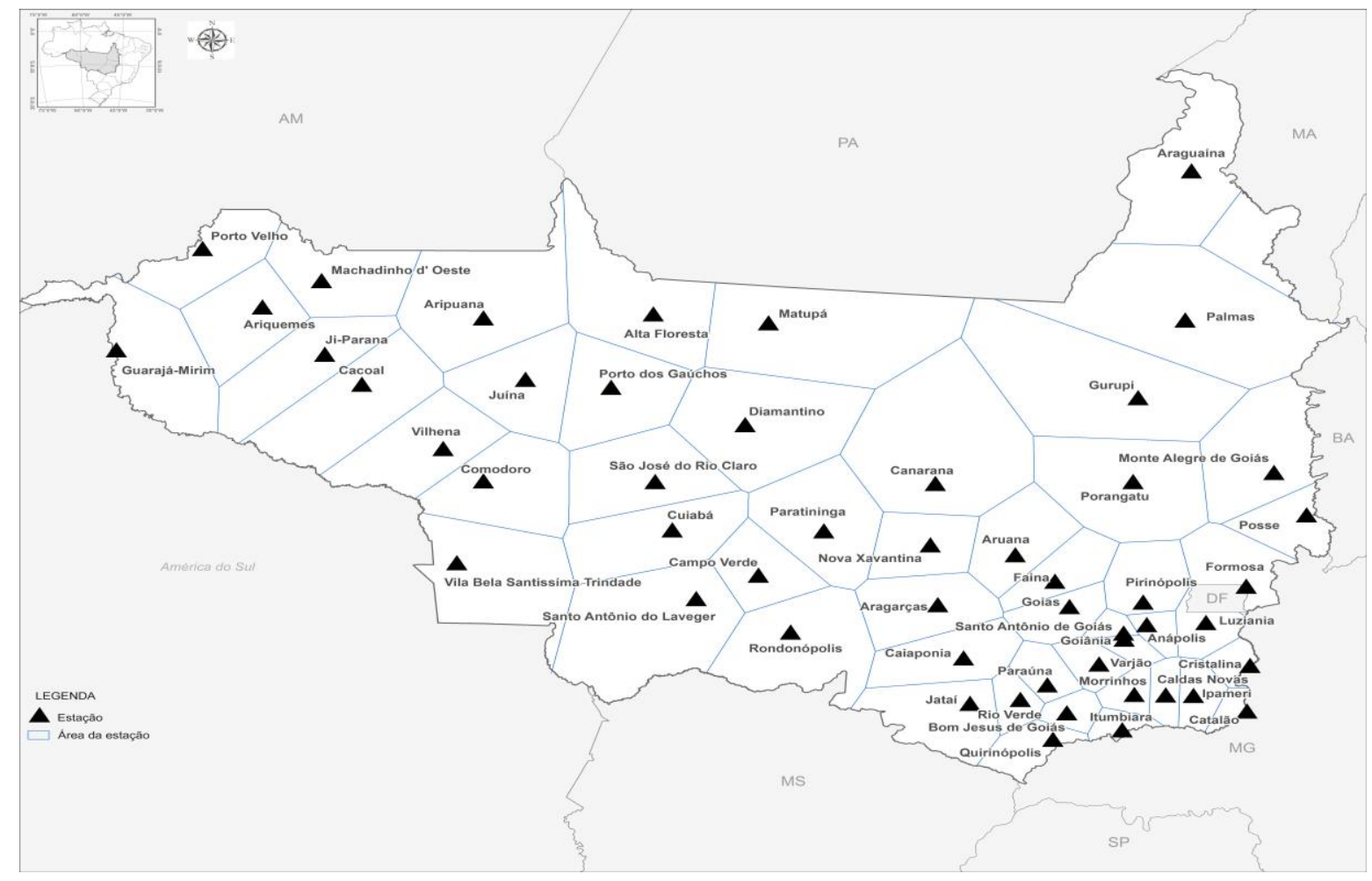

Figura 3. Distribuição geográfica das estações climáticas e suas respectivas áreas de atuação. 

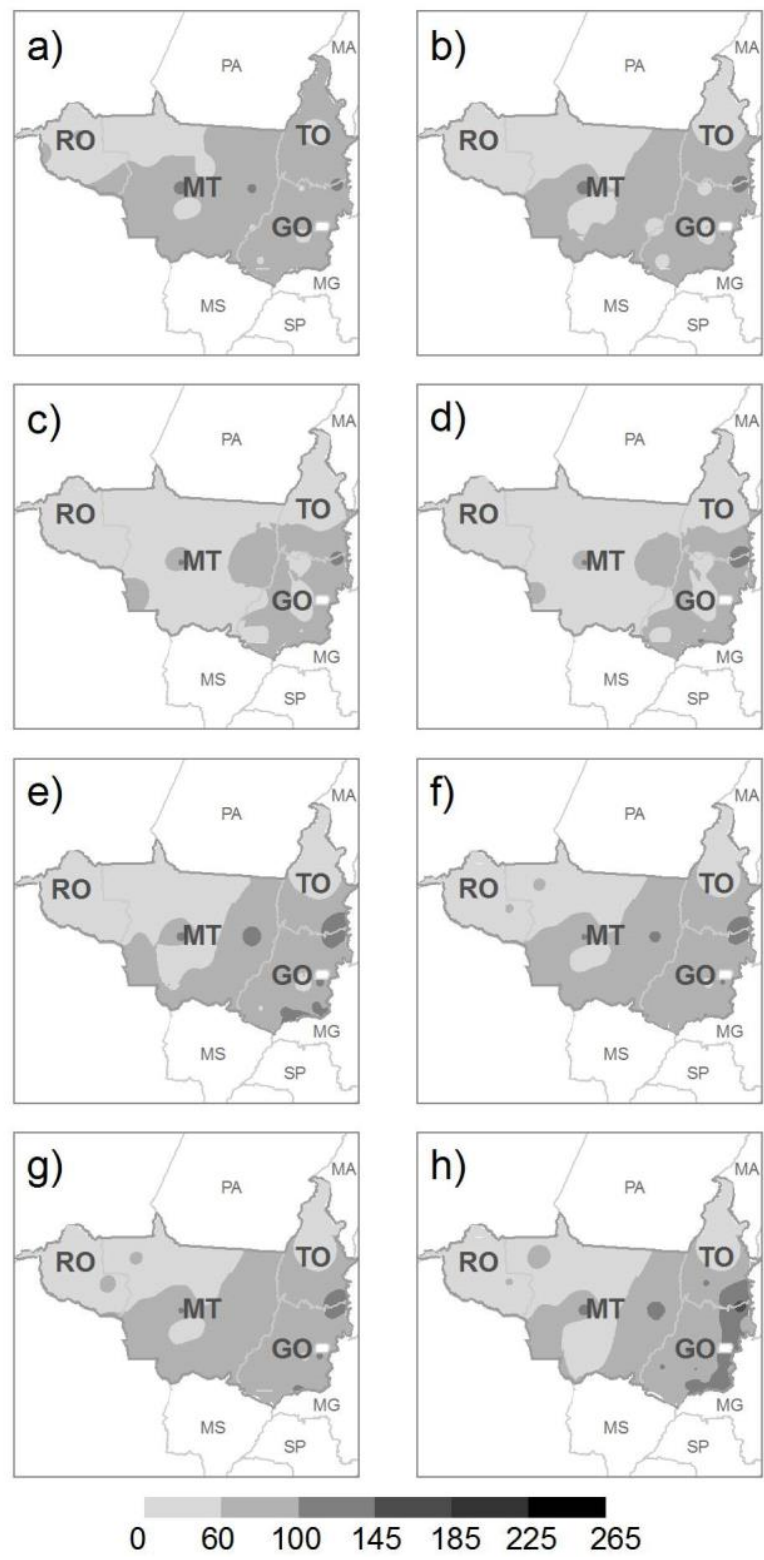

Figura 4. Necessidade de suplementação hídrica $(\mathrm{mm})$ para a cultura do arroz de terras altas considerando semeadura em solo argiloso em: a) $01 / 11$, b) $10 / 11$, c) $20 / 11$, d) $30 / 11$, e) $10 / 12$, f) $20 / 12$, g) $30 / 12$ e h) $10 / 01$. 
A. B. Heinemann et a.
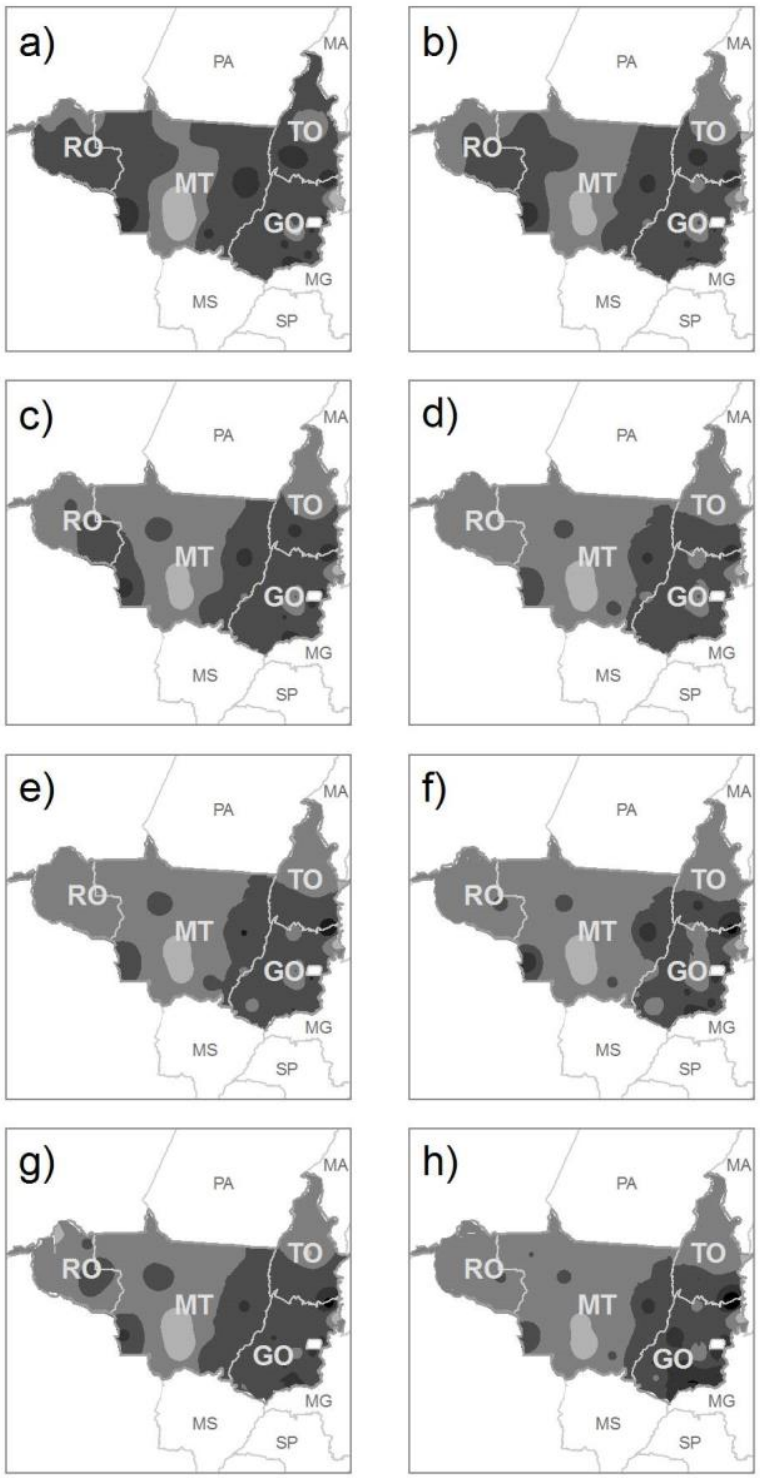

$\begin{array}{lllllll}0 & 60 & 100 & 145 & 185 & 225 & 265\end{array}$

Figura 5. Necessidade de suplementação hídrica $(\mathrm{mm})$ para a cultura do arroz de terras altas considerando semeadura em solo franco argiloso em: a) 01/11, b) 10/11, c) 20/11, d) 30/11, e) 10/12, f) 20/12, g) 30/12 e h) $10 / 01$. 

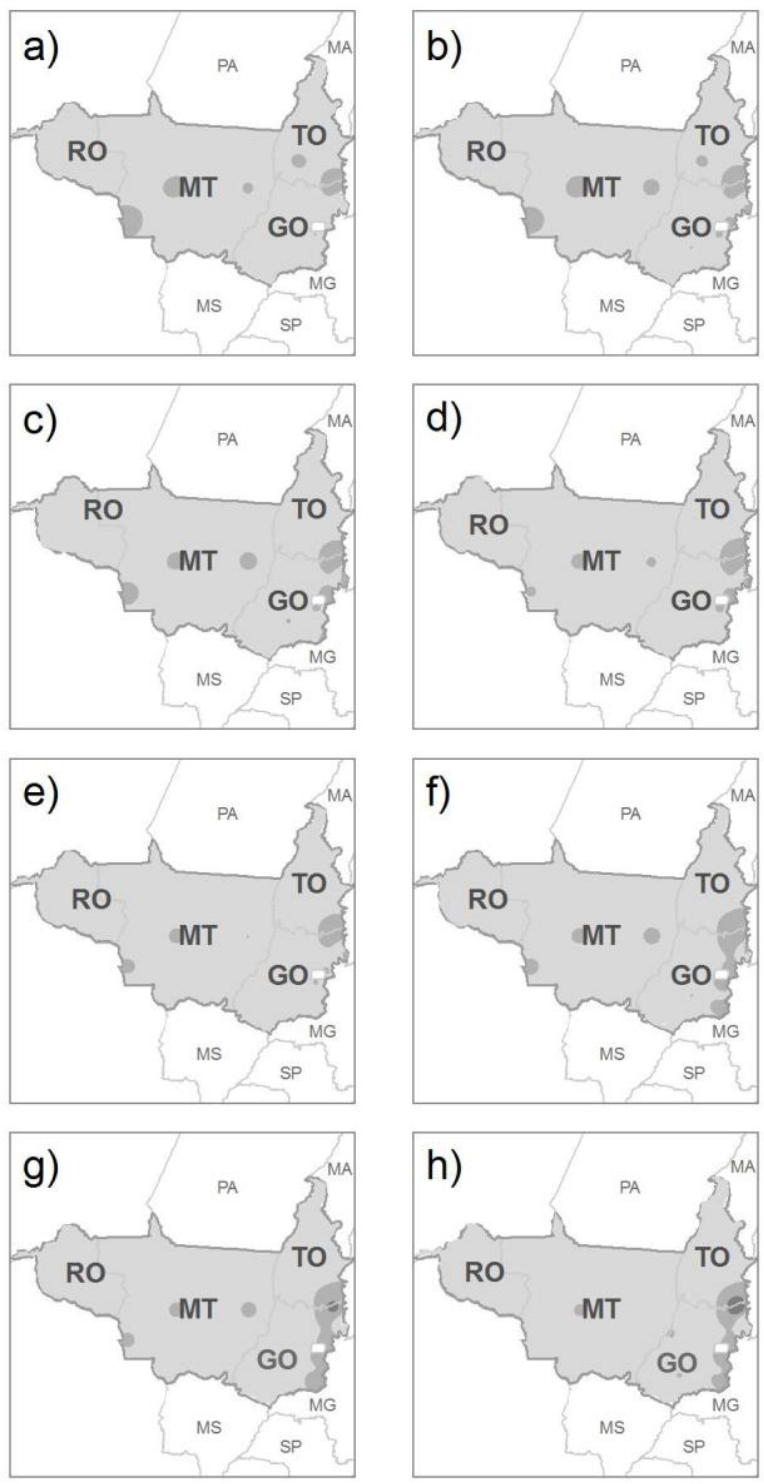

$\begin{array}{lllllll}0 & 60 & 100 & 145 & 185 & 225 & 265\end{array}$

Figura 6. Necessidade de suplementação hídrica $(\mathrm{mm})$ para a cultura do arroz de terras altas considerando semeadura em solo franco argilo arenoso em: a) $01 / 11$, b) $10 / 11$, c) $20 / 11$, d) $30 / 11$, e) $10 / 12$, f) $20 / 12$, g) 30/12 e h) 10/01. 

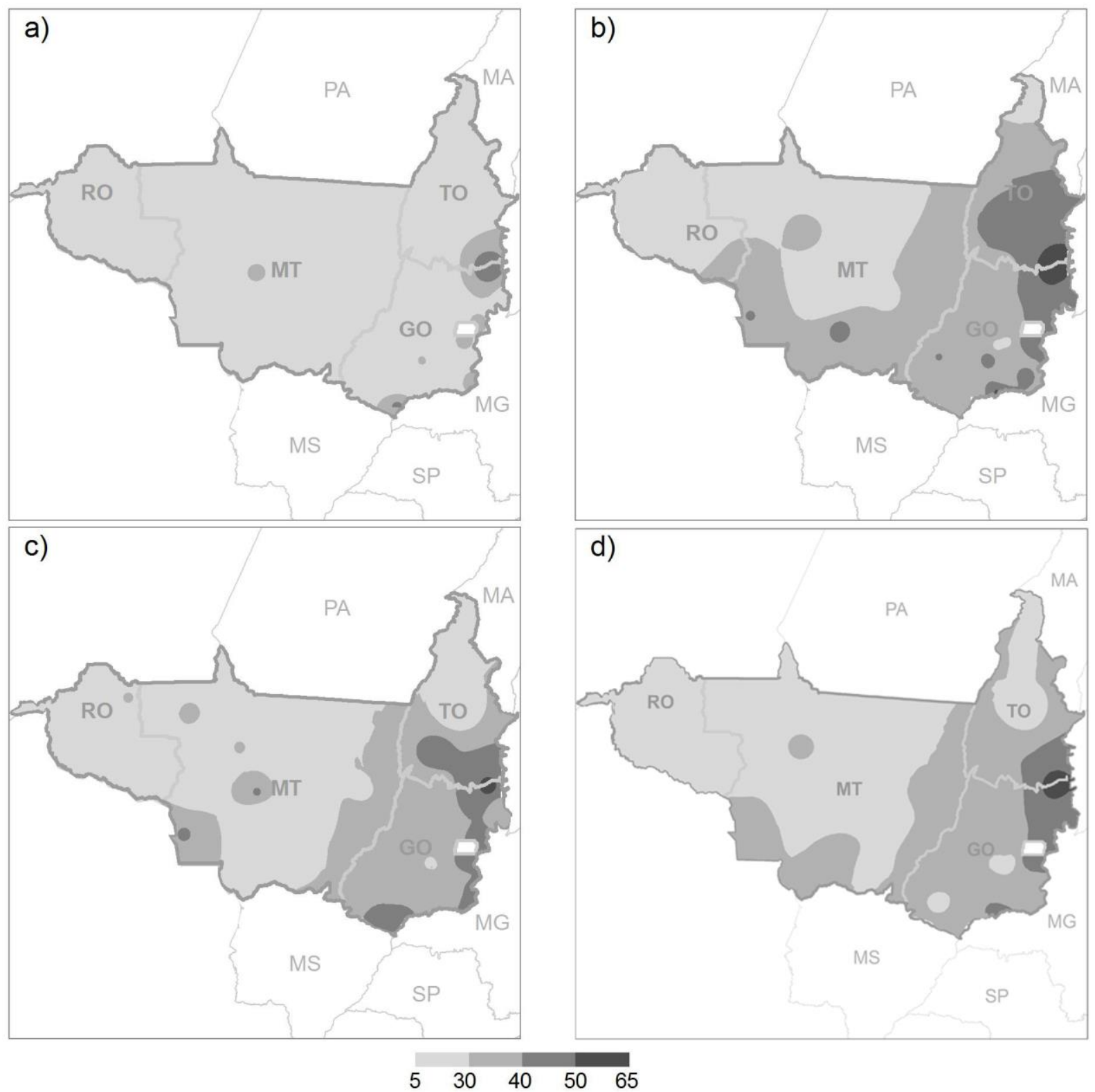

Figura 7. Ganho em produtividade do arroz de terras altas (\%) em razão da irrigação suplementar por aspersão: a) solo franco argilo arenoso, semeadura em 20/11; b) solo franco argiloso, semeadura em 20/11; c) solo franco argilo arenoso, semeadura em 10/01 e d) solo franco argiloso, semeadura em 10/11. 